\title{
Pacemaker implantation through pericardial reflections under fluoroscopic guidance: a novel approach for patients with limited venous access
}

\author{
R Costa*, M Scanavacca, KR Silva, M Martinelli Filho, MS Lacerda, RM Oliveira Jr, ES Crevelari, FB Jatene \\ From 23rd World Congress of the World Society of Cardio-Thoracic Surgeons \\ Split, Croatia. 12-15 September 2013
}

\section{Background}

The purpose of this study was to describe a novel approach for epimyocardial pacemaker implantation under fluoroscopic guidance associated to atrial access through pericardial reflections as an alternative technique for lead implantation in patients with limited venous access.

\section{Methods}

Between June 2006 and November 2011, 15 adult patients underwent epimyocardial atrioventricular pacemaker implantation through a minimally invasive subxiphoid approach and pericardial window. Mean age was $46.4 \pm$ 15.3 years and $9(60.0 \%)$ patients were male. Patients selected for this new surgical approach were not amenable to transvenous lead placement due to: multiple abandoned leads (5), venous occlusion (3), presence of retained lead fragment in the intravascular after previous device extraction (3), tricuspid valve vegetation under treatment (2) and uncorrected intracardiac defects (2).

\section{Results}

All procedures were successfully performed. There were no perioperative complications and no early deaths. The mean operating time for isolated pacemaker implantation was $231.7 \pm 33.5$ minutes. Lead placement on the roof of right atrium through the transverse sinus was possible in 12 patients and in 3 patients the atrial lead was implanted on the left atrium through the oblique sinus. None of the patients displayed pacing or sensing dysfunctions and all

\footnotetext{
* Correspondence: rcosta@incor.usp.br

Cardiovascular Surgery Department, Heart Institute (InCor), Hospital das Clínicas da Faculdade de Medicina da Universidade de São Paulo, São Paulo,
} Brazil

(c) 2013 Costa et al; licensee BioMed Central Ltd. This is an Open Access article distributed under the terms of the Creative Commons Attribution License (http://creativecommons.org/licenses/by/2.0), which permits unrestricted use, distribution, and reproduction in any medium, provided the original work is properly cited.
Cite this article as: Costa et al: Pacemaker implantation through pericardial reflections under fluoroscopic guidance: a novel approach for patients with limited venous access. Journal of Cardiothoracic Surgery 2013 8(Suppl 1):058.
Submit your next manuscript to BioMed Central and take full advantage of:

- Convenient online submission

- Thorough peer review

- No space constraints or color figure charges

- Immediate publication on acceptance

- Inclusion in PubMed, CAS, Scopus and Google Scholar

- Research which is freely available for redistribution

Submit your manuscript at www.biomedcentral.com/submit
( Biomed Central

\section{Biomed Central}

parameters remained stable throughout the follow-up

\section{Conclusion} guidance associated to atrial access through pericardial reproducible patients for whom

Published: 11 September 2013
Epimyocardial pacemaker implantation under fluoroscopic 